\title{
Familial episodic pain syndrome with predominantly lower limb involvement
}

INSERM

\section{Source}

INSERM. (1999). Orphanet: an online rare disease and orphan drug data base. Familial episodic pain syndrome with predominantly lower limb involvement. ORPHA:391392

Familial episodic pain syndrome with predominantly lower limb involvement is a subtype of familial episodic pain syndrome characterized by intense, episodic and/or cyclic pain mainly localized in the distal lower limbs (occasionally affecting upper limbs as well) which is triggered/exacerbated by fatigue, cold exposure and/or weather changes and alleviated with anti-inflammatory medication, that has a tendancy to diminish in frequency with age. Episodes usually occur late in the day, last 15-30 min and associate sweating and a cold sensation of affected area. 